\title{
Families of Children with Repeated Accidents
}

\author{
PETER HUSBAND and PAT E. HINTON \\ From the Department of Paediatrics, Fulham Hospital, London
}

\begin{abstract}
Husband, P., and Hinton, P. E. (1972). Archives of Disease in Childhood, 47, 396. Families of children with repeated accidents. The families of 24 children who attended an accident department with repeated injuries are described. The children frequently had an extrovert type of personality and there were often associated family problems. Coexistent psychiatric or organic illness in other members of the family was common. We suggest that the family background should be investigated whenever children attend a casualty department with repeated injuries, however minor they may be.
\end{abstract}

Accidents are of great concern to all those responsible for the care of children because they are the most common cause of death in childhood over the age of 1 year (General Register Office, 1970). It is well recognized that some children without any physical handicap are more liable to repeated accidents than others (Langford et al., 1953; Manheimer and Mellinger, 1967). It is important to recognize this potentially dangerous pattern of behaviour so that with appropriate help it may be altered. These accidents must not be treated as isolated events but regarded as a recurrent symptom requiring further investigation.

Low (1969) in his welcoming remarks to the Second National Childhood Injury Symposium at Charlottesville, Virginia, said, 'In every accident there is a message, and studies of accidents-indepth and the whole child in the whole accident give great promise in an effort to generalize from the particular.'

In this study, we describe the families of children who have attended the accident department of a teaching hospital in West London with repeated accidents.

\section{Subjects and Methods}

The subjects are 24 children whose ages ranged from 3 to 14 years and who attended the Fulham Hospital Accident Department between March 1968 and February 1970 (Table I). We have defined an accident as any injury, however slight, or any poisoning which resulted in hospital treatment. 10 children were referred to us from the accident department and 13 were seen in the wards after admission. One child was seen when

Received 2 November 1971. her younger sister was admitted because of an overdose of antihistamines. When first seen each child had incurred at least two accidents during the previous 12 months which had necessitated attendance at the accident department. As soon as such a child was recognized we interviewed the mother or, when possible, both parents. At the first interview we pointed out that further injuries might be prevented if together with the parents we were able to understand the reasons for this pattern of behaviour. Each child was examined to exclude any physical cause for the repeated accidents. The interview sessions were informal, free discussion was encouraged, and interview schedules were not used. The families were seen at regular intervals. The frequency of visits depended on the needs of the family and their willingness to attend. The family doctor and health visitor provided additional information in many instances.

\section{Results}

Age. Ages ranged from 2 years 9 months to 14 years with a mean of 7 years 9 months. The mean age of the girls was 9 years 6 months compared with 6 years 11 months for the boys.

Sex. There were 17 boys and 7 girls in the series.

Length of accident history and number of accidents. The children had attended the accident department before referral to us for periods ranging from one month to 12 years with a mean of 3 years 2 months. The total number of accidents for all the children was 136, an average of $5 \cdot 7$ accidents per child. There was no difference between the average number of accidents for males and females. 
Families of Children with Repeated Accidents

TABLE I

Accident History and Family Characteristics

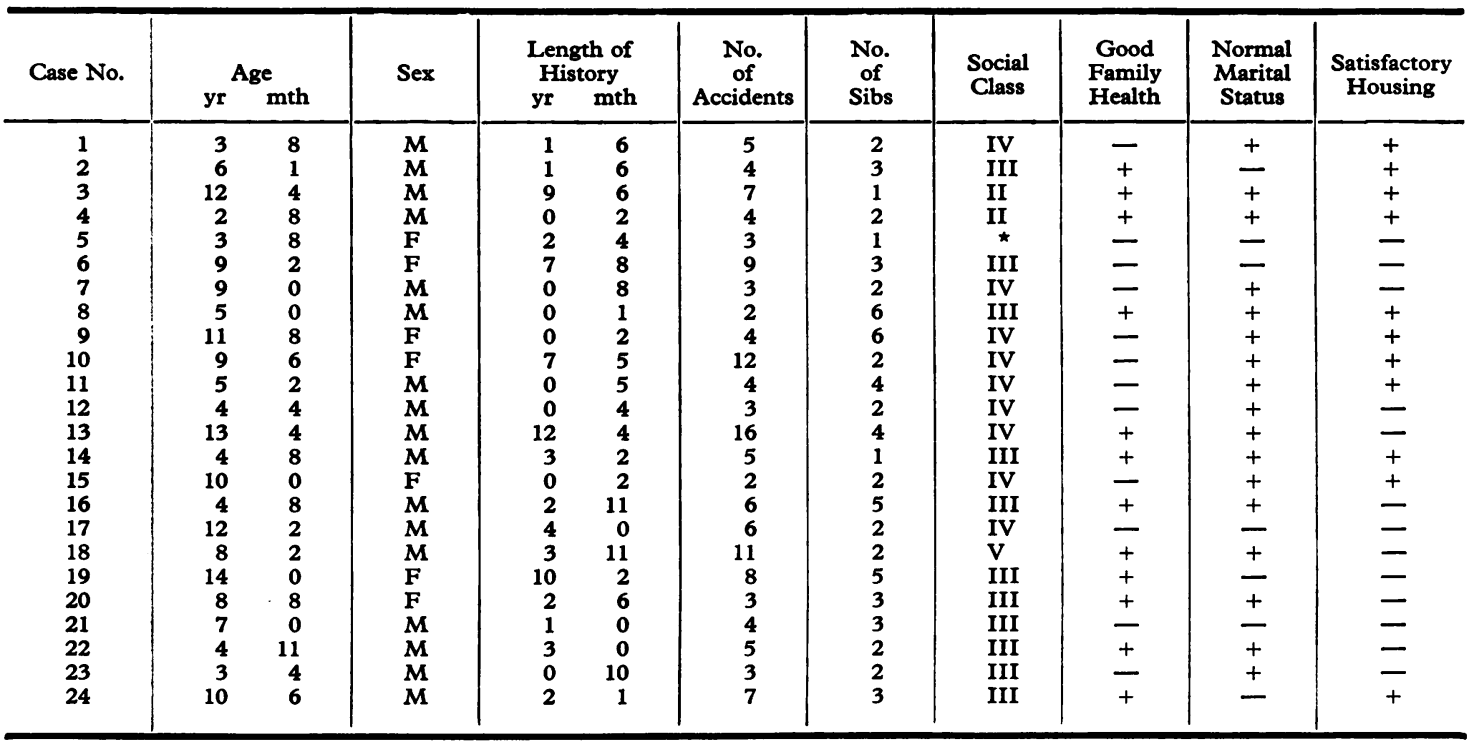

^Mother unmarried and unemployed.

Type of accident. Almost half the accidents were minor limb injuries consisting of bruises, sprains, and cases where trauma was alleged but no sign of injury found. Fractures and ingestion of poisons were more common in the boys (Table II). $\quad 10 \cdot 3 \%$ of the accidents necessitated the child's admission to hospital. $3.6 \%$ of all attendances followed road traffic accidents and these were all in the boys.

TABLE II

Nature of Accidents

\begin{tabular}{|c|c|c|c|}
\hline $\begin{array}{l}\text { Nature of } \\
\text { Accident }\end{array}$ & All Cases & Male & Female \\
\hline $\begin{array}{l}\text { Limb injuries } \\
\text { Cuts } \\
\text { Head injuries } \\
\text { Ingestions } \\
\text { Fractures } \\
\text { Foreign bodies } \\
\text { Eye injuries } \\
\text { Burns } \\
\quad \text { Total }\end{array}$ & $\begin{aligned} 62 & (45 \%) \\
25 & (18 \cdot 4 \%) \\
17 & (12 \cdot 5 \%) \\
10 & (7 \cdot 4 \%) \\
9 & (6 \cdot 7 \%) \\
5 & (3 \cdot 8 \%) \\
4 & (3 \cdot 0 \%) \\
4 & (3 \cdot 0 \%) \\
136 & (100 \%)\end{aligned}$ & $\begin{aligned} 38 & (39 \%) \\
19 & (20 \%) \\
14 & (15 \cdot 3 \%) \\
9 & (9 \cdot 5 \%) \\
8 & (8 \cdot 5 \%) \\
2 & (2 \cdot 2 \%) \\
2 & (2 \cdot 2 \%) \\
3 & (3 \cdot 3 \%) \\
95 & (100 \%)\end{aligned}$ & $\begin{aligned} 24 & (59 \%) \\
6 & (14 \cdot 6 \%) \\
3 & (7 \cdot 3 \%) \\
1 & (2 \cdot 4 \%) \\
1 & (2 \cdot 4 \%) \\
3 & (7 \cdot 2 \%) \\
2 & (4 \cdot 8 \%) \\
1 & (2 \cdot 3 \%) \\
41 & (100 \%)\end{aligned}$ \\
\hline
\end{tabular}

Social class. The families were classified according to the occupation of the head of the family (General Register Office, 1966). 11 families (48\%) belonged to Social Class III and 9 (39\%) to Class IV.
Number of children in family. The mean number of children was $3 \cdot 8$. None of the children in the series was an only child. $46 \%$ of the families had 4 or more children and $25 \%$ had 5 or more children.

Birth order. $25 \%$ of the children were the first born in the family and $37.5 \%$ the last born.

Marital status of parents. In $29 \%$ of the families, the parents were either divorced, separated, or unmarried and not cohabiting. This occurred in $43 \%$ of the girls' families and $23 \%$ of the boys' families.

Housing. Housing was assessed as either satisfactory or unsatisfactory. We relied not only on the parents' description but information was also sought from the family doctor and health visitor. Note was taken of overcrowding, the general condition and age of the property, and facilities available for the children to play safely outside the house. Housing was unsatisfactory in over half the families.

Health of other members of family. In $50 \%$ of the families serious physical or psychiatric illness was present in other members. This occurred more commonly in the girls' families 
(71\%) than in the boys' (41\%). More than one member of the family had a serious illness in $25 \%$ of the families. Overt psychiatric illness was more common in the boys' families whereas organic disease was more common in the girls' families (Table III).

TABLE III

Health of Other Members of the Families Studied (Total families studied $=17$ male, 7 female)

\begin{tabular}{l|c|c}
\hline & Male & Female \\
\hline Overt psychiatric illness in parents & 7 & 1 \\
Death of relative & 1 & 1 \\
Serious organic disease in father & 2 & 3 \\
Serious illness in other relatives & 1 & 3 \\
\hline
\end{tabular}

Two fathers had sustained industrial accidents which had stopped them working for 2 and 3 years, respectively. An elder brother of one of the children had recently sustained a severe penetrating eye injury. In 3 other families the father had serious organic disease.

\section{Case Reports}

Case 10. The father had been out of work for over a year with tuberculosis.

Case 11. The 45-year-old father had rheumatic heart disease of such severity that the consultant physician attending him had advised him to give up work altogether. He struggled on, however, as an hotel porter.

Case 15. The father was an insulin-dependent diabetic.

In two families major illness in a younger sib was a cause of great anxiety. A 2-year-old child had a hemiplegia resulting from birth injury and an 8-month-old baby had Fallot's tetralogy which had already necessitated two major thoracic operations.

In two other families the death of a near relative was felt to play a significant role in causing the child's symptoms.

Case 1. The first child in this family was born with multiple congenital abnormalities and died after 9 months in hospital. The mother's feelings of guilt and disappointment about her first baby had impaired her capacity for mothering and this was a factor in this boy's repeated accidents.

Case 6. This 9-year-old girl was very preoccupied with the death of her uncle and grandfather. She had been told that her uncle would die if he got out of bed. He did this when she was with him and collapsed. He was on the floor for several hours while she stayed with him not realizing that he was dead. She was also with her grandfather when he had a stroke while walking upstairs with her.
Two case histories show the stresses which can be placed on children by illness in other members of the family.

Case 9. This 11-year-old girl talked of how she befriended 'odd characters' who included foreigners, an ugly girl with a squint, and old ladies whom no one else was interested in. Her mother later spoke of her youngest child aged $2 \frac{1}{2}$ years, who had a right hemiparesis following prolonged labour. This Roman Catholic mother had intense feelings of guilt because she had attempted to induce an abortion. Because of the child's handicap, his parents had never been able to chastise him in case this produced fits. The 40-year-old father had been out of work for 3 years as a result of an industrial accident. He had also developed prostatic symptoms and this to him meant that he was 'finished as a man'. An unmarried aunt, psychiatrically ill and with a 4-year-old boy, lived with the family and this girl hated her aunt intensely because she felt that the aunt neglected her child. She remarked that when she had accidents 'she wished it was her aunt'.

Case 15. A 10-year-old girl who sustained a minor head injury and was admitted to hospital 2 days later because she was dizzy and crying a great deal. This was her second attendance at the hospital because of accidents in 3 months, though before this she had been accident free. She looked depressed and she complained so much of the noise in the ward that she had to be nursed in a cubicle. She was very close to her young brother aged 8 months who had Fallot's tetralogy. This had already required two major operations, and on the day she was admitted he was due to go back to hospital for his first outpatient appointment since his latest discharge. She looked after him during the school holidays when her mother was at work. Her parents had not realized her intense fear that when he cried and went blue he might die. After her parents started to discuss his illness more frankly with her, she appeared much happier and she has not had any further accidents over the past 2 years.

\section{Composite Score of Family Health, Marital Status, and Adequacy of Housing}

To each family a point was given for the following:

(a) good health in the family; (b) normal marital status;

(c) satisfactory housing.

Thus the maximum score was 3 and the minimum zero. The results are shown in Table IV. Only 4

\section{TABLE IV}

Composite Score of Family Health, Marital Status, and Adequacy of Housing

\begin{tabular}{c|r|c|c}
\hline Score & All Cases & \multicolumn{1}{|c|}{ Male } & Female \\
\hline 0 & $4(16 \cdot 7 \%)$ & $2(11 \cdot 8 \%)$ & $2(28 \cdot 5 \%)$ \\
1 & $4(16 \cdot 7 \%)$ & $3(17 \cdot 6 \%)$ & $1(14 \cdot 3 \%)$ \\
2 & $12(49 \cdot 9 \%)$ & $8(47 \%)$ & $4(57 \cdot 1 \%)$ \\
3 & $4(16 \cdot 7 \%)$ & $4(23 \cdot 6 \%)$ & - \\
\hline
\end{tabular}


families $(16 \%)$ were given a score of $3.43 \%$ of the girls' families and $29 \%$ of the boys' families had scores of 1 or less.

\section{Presenting Symptom of Family Disturbance}

We found that the child with repeated accidents may often be the presenting symptom of a family disturbance. Other sibs often showed evidence of disturbed behaviour.

Case 2. A 6-year-old boy with 4 accidents in 18 months. There had been marital problems for 7 years and his father had finally left home 5 days before the child was admitted to hospital after ingesting salicylates. His 10-year-old sister posed a behaviour problem at school; his 8-year-old brother showed aggressive behaviour; and his 5-year-old brother was enuretic.

Case 17. A 12-year-old boy with 5 accidents in 2 years. His 6-year-old sister had been referred to hospital a year previously with recurrent sore throats for which no organic cause was found, but it was noted that the mother was depressed. Her husband had left her before the younger child was born, partly as a result of the stresses arising from them living with her parents. A major part of this family's problem was due to the mother being torn between her parents, with whom she still lived, and her children and husband.

Case 22. A 5-year-old boy referred to us after he had sustained his fifth accident in 3 years. His 3year-old brother had also attended the accident department 3 times over this period, and 5 months previously had been referred to a paediatrician because of his bad temper and aggressive behaviour.

\section{Personality of Children}

The children did not conform to one personality type, though frequently the children were described by the parents as being determined, daring, fearless, and showing hyperactive behaviour.

The following remarks were made by parents about their children:

Case 2: 'Always been difficult. Knows no fear. Never cries.'

Case 5: 'Very self-willed.'

Case 9: 'Does things on the spur of the moment. If reprimanded can be difficult and extremely rude. Full of ideas and creative but gets easily frustrated.'

Case 11: 'Very daring. Can't accept explanation of why he shouldn't do something.'

Case 14: 'Doesn't see danger. Has no fear. Likes to feel as big as the others (elder brothers).'

\section{Discussion}

Children with repeated accidents are not uncommon. One child a month was referred to us over the 2-year study period and it seems likely that there were many who were not referred. By only including children with at least two accidents in the preceding 12 months, a group has been selected with a very high accident rate. Krall (1953), in a group of 5- to 8-year-old children, defined her high accident group as those with three or more hospital-attended accidents in a 4-year period. A recent survey of 600 children in Nottingham showed that there was a group that had had 3 or more hospital-attended accidents in a 6-year period. This small group, comprising $3.4 \%$ of the total, accounted for $27 \%$ of all the accidents observed (Head and Husband, 1972, unpublished data). Most of our subjects had sustained more accidents than the minimum criterion; $75 \%$ of the children had 3 accidents and $42 \%$ had 4 or more accidents in the preceding 12 months.

A disturbing finding in our study was the length of time these children attended an accident department and the number of accidents they had incurred. We have previously pointed out that it is easy to treat each episode as an isolated incident (Husband and Hinton, 1969). The accidents are not usually severe and the types of accidents are no different from those found in children who attend on a single occasion. There may, moreover, be an unconscious need not to recognize what is abnormal because recognition demands that action be taken and in this situation it may be difficult to know how to approach the problem.

The presence of overt psychiatric or serious organic illness in other members of the family in over half the families studied was striking. Backett and Johnston (1959), in their study of children who had survived a road accident, found that illness, either maternal or elsewhere in the household, was associated with their vulnerability to accidents. Overt psychiatric illness was found in our series almost entirely in the families of the boys, whereas serious organic disease was found mainly among the girls' families. There is also evidence from general practice that the accident-prone family is also the sick-prone family (McGregor, 1969).

Sobel (1969) and Baltimore and Meyer (1969) have shown that accidental poisoning in childhood is unrelated to the presence of hazard per se. The latter authors compared 52 families with children under 6 years who had ingested poison with control families with no history of accidental poisoning. They found no difference in the mother's knowledge of toxicity of medicines and household products, nor in the number and storage pattern of potentially toxic substances accessible to the children. These findings are of relevance to other childhood accidents. The ecological approach (Watson, 1969), 
where accidents are considered in terms of the person, the event, and the situation, is necessary. Martin (1970), when considering the antecedents of burns and scalds in children, felt that detailed study of the circumstances surrounding an accident allowed definition of the struggles current at the time of injury, which in turn afforded a direct understanding about family interactions. Viewed in this way, accidental injury ceases to be fortuitous, but becomes an event the understanding of which must accompany efforts to help the injured child and his family.

The liability to repeated accidents is clearly multifactorial. The children we have observed, however, often show two features which are of importance: (1) an extrovert personality, and (2) involvement with and confusion by other family problems. These children react to a difficult family situation by hurting themselves. Their personality characteristics have been described by other workers studying children with repeated accidents (Fuller, 1948; Langford et al., 1953; Manheimer and Mellinger, 1967). They are led into situations where they are more frequently faced with accident hazards than other children. At the same time their impulsiveness impairs their ability to make risk-reducing decisions. It seems likely that they act out their difficulties rather than thinking and feeling about them. Some of them may feel guilty about the physical illness in other members of the family and in punishing themselves they are hoping to relieve their anxiety about their unconscious guilt.

The effect of giving these families help by defining the areas in which they have difficulty and then helping them to understand the connexion between these difficulties and the accident pattern, will be the subject of a further report. We have found, however, that when such help is given, the children frequently stop injuring themselves.

\section{REFBRENCES}

Backett, E. M., and Johnston, A. M. (1959). Social patterns of road accidents to children. British Medical fournal, 1, 409.

Baltimore, C., Jr., and Meyer, R. J. (1969). A study of storage, child behavioral traits, and mother's knowledge of toxicology in 52 poisoned families and 52 comparison families. Pediatrics, 44, 816.

Fuller, E. M. (1948). Injury-prone children. American fournal of Orthopsychiatry, 18, 708.

General Register Office (1966). Classification of Occupations. H.M.S.O., London.

General Register Office (1970). Registrar General's Statistical Review of England and Wales for the Year 1968, Part 1, p. 170. H.M.S.O., London.

Husband, P., and Hinton, P. E. (1969). The child with repeated accidents. Midwife and Health Visitor, 5, 279.

Krall, V. (1953). Personality characteristics of accident repeating children. Fournal of Abnormal and Social Psychology, 48, 99.

Langford, W. S., Gilder, R., Jr., Wilking, V. N., Genn, M. M., and Sherrill, H. H. (1953). Pilot study of childhood accidents: preliminary report. Pediatrics, 11, 405.

Low, M. (1969). Welcoming remarks. Second National Childhood Injury Symposium. Pediatrics, 44, 791.

McGregor, R. M. (1969). The Work of a Family Doctor, p. 256. Livingstone, Edinburgh.

Manheimer, D. I., and Mellinger, G. D. (1967). Personality characteristics of the child accident repeater. Child Development, 38, 491.

Martin, H. L. (1970). Antecedents of burns and scalds in children. British Fournal of Medical Psychology, 43, 39.

Sobel, R. (1969). Traditional safety measures and accidental poisoning in childhood. Pediatrics, 44, 811.

Watson, W. (1969). Childhood injuries: a challenge to society. Pediatrics, 44, 794.

Correspondence to Dr. P. Husband, Fulham Hospital, St. Dunstan's Road, London W6 8RF. 